ALMEIDA, A. C. S.; OLIVEIRA, F. C.; SOUSA NETTO, M.; VIEIRA, B. C.; BENETT, C. G. S. Emergência de picãopreto em diferentes profundidades de semeadura e diferentes ambientes. Revista de Agricultura Neotropical, CassilândiaMS, v. 2, n. 1, p. 60-65, jan./mar. 2015.

\title{
EMERGÊNCIA DE PICÃO-PRETO EM DIFERENTES PROFUNDIDADES DE SEMEADURA E DIFERENTES AMBIENTES
}

\section{ANDRÉ CIRILO DE SOUSA ALMEIDA ${ }^{\mathbf{1}}$, FERNANDO CASTRO DE OLIVEIRA ${ }^{\mathbf{1}}$, MAURILIO DE SOUSA NETTO ${ }^{1}$, BRUNA DO CARMO VIEIRA ${ }^{1}$, CLEITON GREDSON SABIN BENETT ${ }^{1}$}

\footnotetext{
1 Instituto Federal Goiano, Urutaí/GO, Brasil, andre_cirillo@hotmail.com, castrodeoliveira.10@gmail.com, mauriliocaldos@hotmail.com,bruna03_@hotmail.com,cbenett@hotmail.com
}

RESUMO: Entender a dinâmica da semente de planta daninha em função da profundidade é fundamental para promover atividade de controle. O objetivo deste trabalho foi avaliar a emergência de sementes de picão-preto submetidas a diferentes profundidades de semeadura, em dois ambientes. O delineamento experimental empregado foi o de blocos casualizados, em esquema fatorial $2 \times 5$, com quatro repetições. Os tratamentos foram constituídos de dois ambientes (condições de campo e ambiente controlado) e cinco profundidades de semeadura $(0,2,4,6$ e $8 \mathrm{~cm})$. As sementes foram semeadas em vasos plásticos com capacidade de $5 \mathrm{~L}$ preenchidos com um Latossolo Vermelho, sendo semeadas 20 sementes por vaso. Avaliou-se o índice de velocidade de emergência e a porcentagem de emergência de plântulas de picãopreto. As avaliações foram realizadas em intervalos de dois dias a partir do dia em que a primeira planta emergiu até que o número de plantas se manteve constante. Os resultados indicam que o índice de velocidade de emergência e a porcentagem de emergência de plântulas de picão-preto foram bastante afetados pela profundidade de semeadura, reduzindo à medida que a profundidade aumentou. Ocorreu diferença também em relação os ambientes, sendo que tanto o índice de velocidade e a porcentagem de emergência foram maiores no ambiente de temperatura constante.

PALAVRAS-CHAVE: Bidens pilosa L., plantas daninhas, velocidade de emergência.

\section{EMERGENCE OF BEGGAR-TICK IN DIFFERENT DEPTHS OF SEEDING AND ENVIRONMENTS}

\begin{abstract}
Understand the dynamics of weed seed by depth is critical to promote their control. The objective of this study was to evaluate the seedling emergence of beggar-tick under different sowing depths and environments. The experimental design was a randomized block in $2 \times 5$ factorial, with four replications. Treatments consisted of two environmental conditions (field conditions and controlled environment) and five sowing depths $(0,2,4,6$ and $8 \mathrm{~cm}$ ). Twenty beggar-tick seeds were sown in plastic pots containing $5 \mathrm{~L}$ of a Red Latosol. The emergency speed index and the percentage of emergence of beggar-tick seedlings were evaluated at intervals of two days from the day the first plant emerged until the number of plants remained constant. The results indicate that the emergency speed index and the percentage of emergence of beggar-tick seedlings were highly affected by sowing depth, reducing with increasing of depth. There were also differences between the environments, and the emergency speed index and the percentage of emergence of beggar-tick seedlings were higher in constant temperature environment.
\end{abstract}

KEY WORDS: Bidens pilosa L., weeds, emergence speed. 


\section{INTRODUÇÃO}

Plantas daninhas são espécies que se desenvolvem em áreas de cultivos agrícolas, em conjunto com a espécie cultivada, interferindo em seu desenvolvimento e na sua produção, pois competem por água, luz, nutrientes e, também, podem causam efeito alelopático, provocando a redução qualitativa e quantitativa da produção (LORENZI, 2000).

A espécie Bidens pilosa L., popularmente conhecida como picão-preto, é uma planta daninha originária da América Tropical e disseminada para várias regiões tropicais e subtropicais do mundo, sendo uma das mais importantes plantas daninhas na América do Sul (KISSMANN; GROTH, 1999). No Brasil ocorre em quase todo o território, porém, sua presença é maior nas áreas agrícolas das regiões Sul e Centro-Oeste. É uma invasora que, além de competir com a cultura, pode servir de hospedeiro de pragas e doenças (KISSMANN, 1997). O picão-preto é uma das principais plantas daninhas hospedeira de nematoides do gênero Meloidogyne, também conhecidos como nematoides de galhas (CARMONA; VILLAS BÔAS, 2001).

A reprodução do picão-preto ocorre via semente e pode ser encontrado durante todo o ano, mas as maiores infestações ocorrem durante as estações mais quentes, ou seja, na primavera e verão (KISSMANN, 1997). A formação de sementes é intensa, podendo chegar a 3.000 por planta e apesar de pequena proporção das sementes terem germinação imediata após a maturação (KISSMANN; GROTH, 1999), o número produzido pode comprometer a colheita mecanizada (SANTOS; CURY, 2011).

A germinação desuniforme observada nas sementes de picão-preto ocorre devido à dormência, que proporciona a sobrevivência e a viabilidade do banco de sementes em condições externas adversas (CARMONA; MURDOCH, 1995). As sementes de picão-preto germinam facilmente até $2,0 \mathrm{~cm}$ de profundidade, podendo permanecer dormentes por vários anos em profundidades superiores a $10 \mathrm{~cm}$ (SAHOO; JHÁ, 1998; MUNIZ FILHO et al., 2004). Mecanismos de dormência possibilitam que sementes enterradas profundamente no solo apresentem ao por volta de $80 \%$ de germinação, após três a cinco anos (LORENZI, 2000).

A distribuição vertical de sementes ao longo do perfil do solo, que apresenta estreita correlação com o tipo de preparo do solo, sendo importante por submeter às sementes em diferentes condições ambientais. O conhecimento da dinâmica da germinação e da emergência de propágulos de plantas daninhas em diferentes profundidades do solo é fundamental para a proposição de métodos mais racionais e eficientes de seu manejo (YAMASHITA et al., 2005).

As sementes de picão-preto também podem germinar dentro de um grande intervalo de temperatura, 20 a $35^{\circ} \mathrm{C}$ é a melhor faixa de temperatura para germinação de sementes de picão-preto, com o máximo (70\%) ocorrendo a $25^{\circ} \mathrm{C}$ (CHIVINGE, 1996).

Este estudo teve como objetivo avaliar a emergência de sementes de picão-preto submetidas a diferentes profundidades de semeadura em diferentes ambientes.

\section{MATERIAL E MÉTODOS}

O experimento foi realizado no Instituto Federal de Educação, Ciência e Tecnologia Goiano, IF Goiano - Câmpus Urutaí, Goiás, em condições de laboratório com temperatura de $25 \pm 2{ }^{\circ} \mathrm{C}$, umidade relativa (UR) $70 \pm 10 \%$ e fotoperíodo de 12 horas e em condições de campo com temperatura máxima média no período de condução do experimento de $28{ }^{\circ} \mathrm{C}$ e a 
mínima média de $14{ }^{\circ} \mathrm{C}$, com umidade relativa de $60 \%$. O experimento foi conduzido no mês de julho de 2014.

O delineamento experimental utilizado foi o de blocos casualizados em esquema fatorial $2 \times 5$, com quatro repetições, sendo o primeiro fator constituído por dois ambientes (condições de campo e ambiente controlado) e o segundo fator constituído por cinco profundidades de semeadura $(0,2,4,6$ e $8 \mathrm{~cm})$.

As sementes foram coletadas na área do Campus em plantas apresentando maturidade fisiológica. O armazenamento até a data de semeadura (15 dias) foi feito em sacos de papel, em condições ambientais de laboratório. Antes da semeadura foi realizado o teste de germinação das sementes no Laboratório de Sementes do Campus, as quais apresentaram 72\% de germinação.

A semeadura foi realizada em vasos plásticos com capacidade de $5 \mathrm{~L}$. As diferentes profundidades de semeadura foram obtidas com o uso de uma estaca graduada em centímetros. Cada unidade experimental foi composta por um vaso onde foram semeadas 20 sementes. O substrato utilizado foi solo peneirado, oriunda de um Latossolo vermelho distroférrico de textura argilosa (521 $\mathrm{g} \mathrm{kg}^{-1}$ de argila, $191 \mathrm{~g} \mathrm{~kg}^{-1}$ de silte, e $285 \mathrm{~g} \mathrm{~kg}^{-1} \mathrm{de}$ areia).

Foram realizadas irrigações diárias para manter o solo com disponibilidade de umidade suficiente para garantir a germinação das sementes. As avaliações foram realizadas a cada dois dias, a contar do dia em que a primeira planta emergiu até que o número de plantas se tornou constante no tratamento mais veloz.

As sementes foram consideradas germinadas quando a protrusão dos folíolos se tornou visível sobre o solo. No caso dos aquênios localizados na superfície do solo, a emergência foi considerada quando as plântulas apresentavam início de abertura dos cotilédones.

As características avaliadas foram a porcentagem de emergência e o índice de velocidade de emergência (IVE), obtido pela equação adaptada de Maguire (1962), IVE= $(\mathrm{E} 1 / \mathrm{N} 1)+(\mathrm{E} 2 / \mathrm{N} 2)+\ldots+(\mathrm{En} / \mathrm{Nn})$, onde $\mathrm{E} 1+\mathrm{E} 2+\ldots \mathrm{En}=$ número de plantas emergidas computadas na primeira, segunda e última contagem, e $\mathrm{N} 1+\mathrm{N} 2+\ldots \mathrm{Nn}=$ número de dias da semeadura a primeira, segunda e última contagem.

Os resultados foram submetidos à análise de variância e quando observado efeitos significativos, às médias foram submetidas à análise de regressão, em função das profundidades de semeadura. O nível de significância adotado foi de 5\%.

\section{RESULTADOS E DISCUSSÃO}

Os valores médios para o índice de velocidade de emergência (IVE) e porcentagem de germinação são apresentados na Tabela 1.

Em relação ao IVE pode-se observar que houve diferença significativa tanto para os ambientes quanto para as profundidades de semeadura, ocorrendo também interação entre esses fatores como pode ser observado na Tabela 1. O IVE foi maior no ambiente controlado do que no campo indicando que as sementes emergiram mais rápido no ambiente com temperatura constante. Quando se compara as diferentes profundidades de semeadura pode-se observar que o IVE apresentou valor bem mais elevado quando as sementes foram semeadas na superfície do solo e à medida que se aumentou a profundidade de semeadura esse índice diminuiu de forma considerável, sendo que nas profundidades de 6 e $8 \mathrm{~cm}$ não houve emergência de plântulas. As menores profundidades causam menor gasto de energia da 
plântula para vencerem as barreiras físicas impostas pelo solo e por isso ocorre as maiores velocidades de emergência.

Tabela 1. Médias do índice de velocidade de emergência (IVE) e porcentagem de emergência de plantas de picão-preto em diferentes ambientes e profundidades de semeadura. Urutaí - GO, 2014

\begin{tabular}{ccc}
\hline \multirow{2}{*}{ Fator de Variação } & \multicolumn{2}{c}{ Quadrado médio } \\
\cline { 2 - 3 } & IVE & Porcentagem de emergência \\
\hline Ambiente & $63,36^{* *}$ & $11,11^{* *}$ \\
Profundidade & $155,76^{* *}$ & $134,08^{* *}$ \\
Ambiente x Profundidade & $33,38^{*}$ & $1,91^{\mathrm{ns}}$ \\
C.V.(\%) & 32,60 & 24,84 \\
\hline & Plântulas dia & $\%$ \\
Ambiente Controlado & $2,46 \mathrm{a}$ & $27,00 \mathrm{a}$ \\
Condições de Campo & $1,03 \mathrm{~b}$ & $20,75 \mathrm{~b}$ \\
\hline
\end{tabular}

Médias na mesma coluna, seguidas por letras iguais, não diferem entre si pelo teste $\mathrm{F}$ a $5 \%$ de probabilidade $(\mathrm{P}<0,05)$ para cada variável. ${ }^{* *}$ significativo a $1 \%$ probabilidade, ${ }^{* *}$ significativo a $1 \%$ de probabilidade e ${ }^{\text {ns }}$ não significativo, respectivamente.

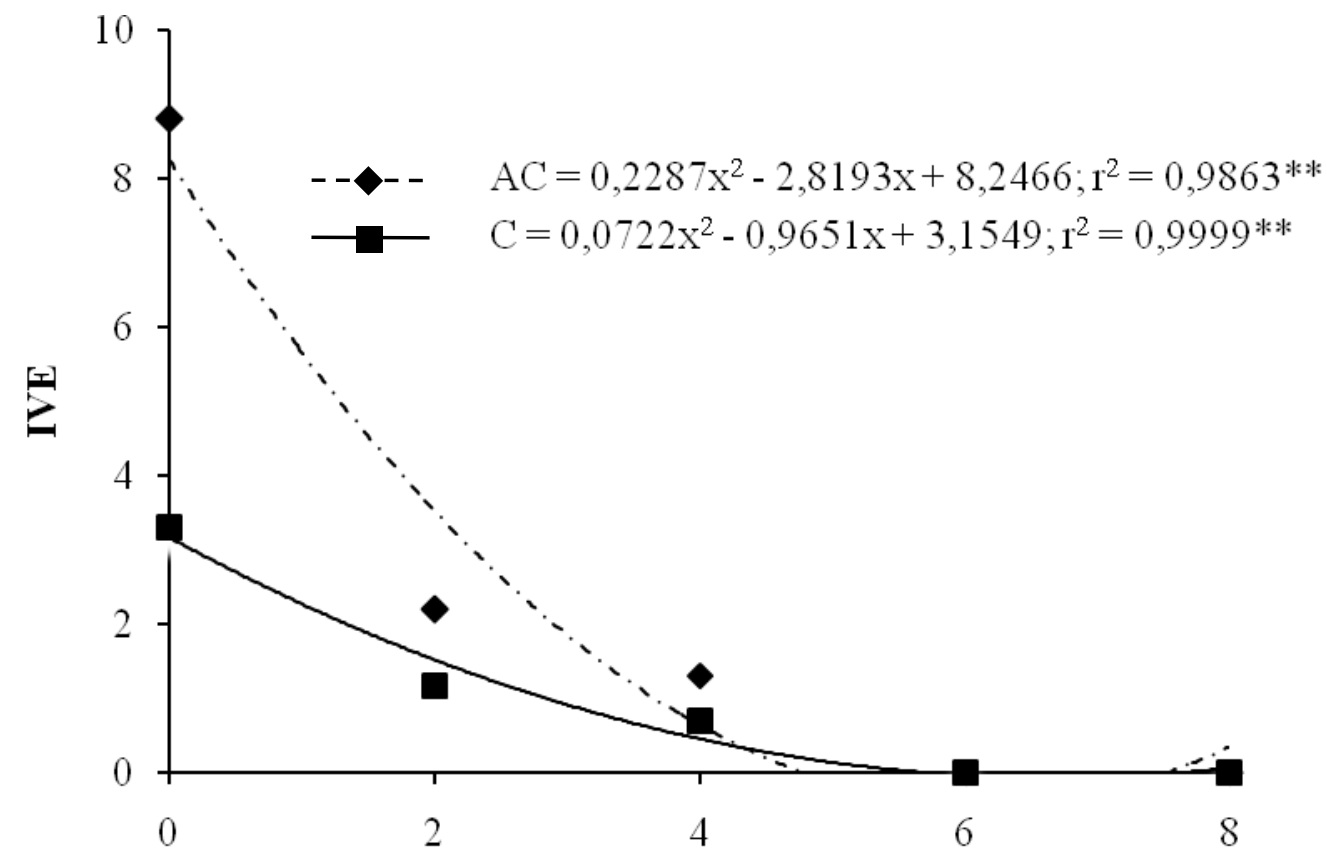

Profundidade de semeadura $(\mathrm{cm})$

Figura 1. Índice de velocidade de emergência (IVE) em função dos ambientes. $\mathrm{AC}=$ Ambiente controlado; C = Campo. Urutaí - GO, 2014

Esses valores de IVE estão próximos aos encontrados por Souza et al. (2009) que, ao avaliarem a emergência de picão-preto em profundidades de semeadura variando de 0 a $5 \mathrm{~cm}$ em casa de vegetação, verificaram que ocorreu significativa redução de IVE conforme se aumentou a profundidade de semeadura. Muniz Filho et al. (2004) também encontraram resultados semelhantes ao avaliarem a capacidade de emergência de picão-preto em profundidades de semeadura variando de 2 a $10 \mathrm{~cm}$ em condições de campo, com o IVE reduzindo à medida em que se aumenta a profundidade de semeadura, porém esses autores verificaram emergência de plantas até a profundidade de $10 \mathrm{~cm}$, mostrando a dinâmica e capacidade de germinação que essa planta apresenta. 
Em relação à porcentagem de germinação ocorreu diferença significativa entre os ambientes e também entre as profundidades de semeadura, não havendo interação entre esses dois fatores. Verificou-se maior porcentagem de emergência de plantas no ambiente controlado em relação ao campo. Esses dados diferem dos encontrados por Carmona e Villas Bôas (2001) que ao avaliarem o efeito da profundidade das sementes no perfil do solo e da presença da palha, na germinação, dormência e viabilidade de sementes de B. pilosa, ao longo de um ano, verificou-se que na época do enterrio, ao redor de $20 \%$ e $70 \%$ das sementes deixaram de germinar nas condições de temperatura alternada e constante, respectivamente.

Em relação à profundidade de semeadura pode-se verificar que a maior porcentagem de emergência ocorreu quando as sementes foram semeadas na superfície dos vasos, diminuindo à medida que aumentou-se a profundidade das sementes, sendo que nas profundidades de 6 e $8 \mathrm{~cm}$ não houve emergência de plântulas. A baixa porcentagem de emergência mesmo na superfície $(56,88 \%)$ pode ser explicada pelo fato de o picão-preto apresentar dormência de suas sementes, dessa forma mesmo em condições favoráveis à germinação algumas sementes podem permanecer dormentes e não germinarem. Para as sementes que foram enterradas a baixa ou a ausência de germinação ocorreu devido ao fato de o solo apresentar uma barreira física para a emergência das sementes e também porque a luz pode estimular a germinação das sementes. Klein e Felippe (1991) verificaram que a germinação de sementes de picão-preto aumentou de 50\% no escuro para $70 \%$ em presença de luz, com temperatura constante.

Os dados de emergência estão de acordo com os de vários autores. Sahoo \& Jhá (1998) observaram redução de 66\% na emergência de plântulas de picão-preto quando as sementes foram semeadas a apenas $2 \mathrm{~cm}$ de profundidade. De acordo com Lorenzi (2000) a emergência de plântulas de picão-preto é decorrente de aquênios localizados até $1 \mathrm{~cm}$ de profundidade. Carmona e Villas Bôas (2001) verificaram, para regiões de cerrado, que a germinação e o decréscimo de sementes de picão-preto são mais rápidos na superfície do solo em relação às sementes enterradas a $10 \mathrm{~cm}$ de profundidade. Yamashita et al. (2005), ao avaliarem a resposta à diferentes profundidades de semeadura de picão-preto, também verificaram decréscimo na emergência à medida que se aumentou a profundidade de semeadura. Souza et al. (2009) também verificaram expressiva redução na emergência de picão-preto a partir de $2 \mathrm{~cm}$ de profundidade de semeadura.

A variação da capacidade germinativa do picão-preto nos experimentos conduzidos nas diferentes épocas do ano é um ponto importante no manejo dessa planta (Souza et al., 2009). O banco de sementes e propágulos vegetativos no solo constitui a principal fonte de regeneração de plantas daninhas em áreas agrícolas (CARMONA, 1992), assim solos submetidos ao preparo convencional apresentam densos bancos de semente, em razão da incorporação dos propágulos. Por outro lado a técnica do plantio direto acelera o decréscimo de sementes de picão-preto no solo por concentrá-las próximo à superfície (SANTOS; CURY, 2011). Dessa forma é importante sabermos a dinâmica populacional de sementes nos solos para traçarmos estratégias eficazes de controle.

\section{CONCLUSÕES}

A velocidade e a porcentagem de emergência de plântulas de picão-preto reduzem significativamente com o aumento da profundidade de semeadura.

Em condições de temperatura constante ocorreu uma maior velocidade e porcentagem de emergência de plântulas de picão-preto. 


\section{REFERÊNCIAS BIBLIOGRÁFICAS}

CARMONA, R. Problemática e manejo de bancos de sementes de invasoras em solos agrícolas. Planta Daninha, Viçosa-MG, v. 10, n. 1/2, p. 5-16, 1992.

CARMONA, R.; MURDOCH, A. J. Interactions of temperature and dormancy-relieving compounds on the germination of weed seeds. Seed Science. Reserch.Cambridge, v. 5, n. 4, p. 227-236, 1995.

CARMONA, R.; VILLAS BÔAS, H. D. C. Dinâmica de sementes de Bidens pilosa no solo. Pesquisa Agropecuária Brasileira, Brasília-DF, v. 36, n. 3, p. 457-463, 2001.

CHIVINGE, O. A. Studies on the germination and seedling emergence of Bidens pilosa and its response to fertilizer application. Trans. Zimbabwe Scientific Association, Harare, v. 70, n. 1, p. 1-5, 1996.

KISSMANN, C. G. Bidens pilosa L. e Bidens subalternans DC. São Paulo-SP: BASF Brasileira. 1997. 6 p.(mimeografado).

KISSMANN, K. G.; GROTH, D. Plantas infestantes e nocivas. 2. ed. São Paulo-SP: BASF, 1999. Tomo II. $978 \mathrm{p}$.

KLEIN, A.; FELIPPE, G. M. Efeito da luz na germinação de sementes de ervas invasoras. Pesquisa Agropecuária Brasileira, Brasília-DF, v. 26, n. 7, p. 955-966, 1991.

LORENZI, H. Plantas daninhas do Brasil: terrestres, aquáticas, parasitas, tóxicas e medicinais. 3. ed. Nova Odessa-SP: Instituto Plantarum, 2000. 608 p.

MAGUIRE, J. D. Speed of germination aid selection and evaluation for seedling emergence and vigor. Crop Science., Madson, v. 2, n. 2, p. 176-177, 1962.

MUNIZ FILHO, A.; CARNEIRO, P. T.; CAVALCANTI, M. L. F.; ALBUQUERQUE, R. C. Capacidade de emergência de picão-preto em diferentes profundidades de semeadura. Revista de Biologia e Ciências da Terra, Campina Grande-RN, v. 4, n. 1, p. 1-6, 2004.

SAHOO, U. K.; JHA, L. K. Effect of depth and duration of burial on seed viability and dormancy of Bidens pilosa L. and Richardsonia pilosa H. B. K. Seed Science Research, Cambridge, v. 25, n. 1, p. 5-10, 1998.

SANTOS, J. B.; CURY, J. P. Picão-preto: uma planta daninha especial em solos tropicais. Planta Daninha, Viçosa-MG, v. 29, n. spe. p. 1159-1171, 2011.

SOUZA, M. C. et al. Emergência de Bidens pilosa em diferentes profundidades de semeadura. Planta Daninha, Viçosa-MG, v. 27, n. 1, p. 29-34, 2009.

YAMASHITA, O. M. et al. Efeito de profundidade de semeadura na emergência de picãopreto (Bidens pilosa) e fedegoso (Cassia occidentalis). Revista de Ciências AgroAmbientais, Alta Floresta-MT, v. 3, n. 1, p. 84-91, 2005. 